\title{
Interexaminer and intraexaminer reliability of the microperimeter MP-1
}

${ }^{1}$ Department of Ophthalmology, Medical University of Vienna, Vienna, Austria

${ }^{2}$ Department of Statistics and Probability Theory, University of Technology, Vienna, Austria

Correspondence: PV VécseiMarlovits,

Department of

Ophthalmology,

Medical University of

Vienna,

Waehringer Guertel, 18-20,

Vienna A-1090, Austria

Tel: +43140400 7931;

Fax: + 431404007932 .

E-mail: veronika.vecsei-

marlovits@

meduniwien.ac.at

Received: 5 February 2008 Accepted in revised form: 25 June 2008

Published online: 1 August 2008

No funding or support was provided

None of the authors have any commercial interest in any material or method mentioned

\begin{abstract}
Purpose To evaluate the interexaminer and intraexaminer reliability of macular microperimetry using the microperimeter MP-1.

Methods Participants: Fifteen healthy volunteers younger than 40 years of age (Group 1), 15 healthy subjects over 60 years (Group 2), and five patients with age-related macular degeneration (Group 3). Observation procedure: Two examiners (E1 and E2) measured, in random order, interexaminer (E2-E1a) reliability. Another examination was undergone by one of the examiners a week later to evaluate the intraexaminer (E1b-E1a) reliability. Main outcome measures: Macular sensitivity (mean threshold (decibel)) and stability of fixation were determined using MP1 microperimetry. Agreement was analysed by means of Bland-Altman plots and by the determination of the intraclass correlation coefficient.
\end{abstract}

Results The interexaminer (E2-E1a) and the intraexaminer (E1b-E1a) differences in the mean threshold values were not statistically significant $(P=0.850,95 \%$ confidence Interval $(\mathrm{CI})=-0.265$ to $0.319 ; P=0.246,95 \%$ $\mathrm{CI}=-0.099$ to 0.375 , respectively). Limits of agreement and intraclass correlation coefficients also showed good agreement in each group.

Conclusions A good reliability was found for the mean threshold values in all the three groups, indicating examiner-independent measurements.

Eye (2009) 23, 1052-1058; doi:10.1038/eye.2008.237; published online 1 August 2008

Keywords: microperimetry; reliability; fixation stability; macular sensitivity
B Weingessel', S Sacu', PV Vécsei-Marlovits', A Weingessel' ${ }^{2}$, S Richter-Mueksch ${ }^{1}$ and U Schmidt-Erfurth ${ }^{1}$

\section{Introduction}

Microperimetry has been implemented clinically to achieve a direct correlation between retinal pathologies and functional defects by providing simultaneous observation of the fundus and a correction for eye movements during the perimetric examination.

Over the past several years, the scanning laser ophthalmoscope (SLO) was the only commercially available microperimeter. ${ }^{1-3}$ Previous studies have shown the value of this method for the follow-up of patients with progressive macular diseases. ${ }^{4-6}$ An important disadvantage of the SLO was the lack of a real-time fundus-tracking function. In addition, the SLO can no longer be obtained.

Recently, a new microperimeter, the Micro Perimeter 1 (MP1; Nidek Technologies, Italy), has been introduced to the market. This instrument includes automated full-threshold perimetry software and a real-colour fundus image acquisition. Compared to the SLO, covering a field of $33 \times 22^{\circ}$, an enlarged area can be tested with the integrated $45^{\circ}$ fundus camera. After the examination, an overlay of the perimetric findings onto the colour image of the central retina is provided. For a follow-up exam, the previous examination data can be loaded, so as to stimulate the retina exactly in the same location and with the same intensities used in the first exam, allowing an accurate comparison of the functional assessments of the two exams.

As with any new diagnostic instrument, the validity of the data acquired might be reduced by variability, both interdevice and interoperator. ${ }^{7}$ Interoperator variability was previously studied for other medical devices like optical coherence tomography (OCT), ${ }^{8}$ the BVI ultrasonic Pachymeter, ${ }^{9}$ the GD $\times \mathrm{VCC}^{7}$ and the prototype of the ACMaster. ${ }^{10}$ Other devices for visual field testing such as the 
Humphrey or Octopus perimeters were analysed in detail for test/retest variability. ${ }^{11-15}$ Intra- and interrater agreement of psychophysical tests was investigated regarding the Functional Field Score ${ }^{16}$ and cumulative defect curves. ${ }^{17}$ The interobserver agreement interpreting the test results of different devices was also examined, ${ }^{18,19}$ but no studies concerning intra- and interoperator reliability of the examination itself were found.

The aim of the present study was to quantify the interexaminer and intraexaminer reliability and variability of the MP-1.

\section{Methods}

\section{Participants}

We assessed 35 eyes of 35 consecutive patients in our institutional study and divided them into three different groups as follows. Group 1 (young): 15 eyes from 15 healthy young volunteers with no history of ocular diseases, other than ametropia. Group 2 (old): 15 eyes of 15 healthy subjects over 60 years of age, with a history of cataract surgery at least 4 months before the study, with no optical opacities and a macula with no pathological findings. Group 3 included five patients with age-related macular degeneration (ARMD) (Age-Related Eye Disease Study classification III: Intermediate ARMD - absence of advanced ARMD in both eyes and at least one eye, with $20 / 32$ vision or better, with at least one large drusen $(\geqslant 125 \mu \mathrm{m})$, extensive intermediate drusen, geographic atrophy not involving the centre of the macula, or any combination of these).

In each group, one eye was included for examination, according to the randomization scheme.

Each patient underwent a routine ophthalmologic examination, including funduscopy and determination of best-corrected visual acuity. Distance visual acuity at $4 \mathrm{~m}$ was tested using the Early Treatment Diabetic Retinopathy regimen, best-corrected refraction, and retro-illuminated charts.

Optical coherence tomography was used to quantify retinal thickness. We certify that all applicable institutional and governmental regulations concerning the ethical use of human volunteers were followed during this research.

\section{Perimetric examination}

All subjects in the study were tested for the first time during the baseline exam to avoid a possible learning effect. Perimetric examination was performed after explanation of the method to all participants and an adaptation time to the darkened room of $5 \mathrm{~min}$.
To assess interexaminer reliability and variability, microperimetry was performed by two examiners on the same day. Examiner 1 (E1) was a newly recruited staff member with no prior experience in operating any diagnostic or photographic equipment. Examiner 2 (E2) was a skilled ophthalmologist with experience in operating most types of ophthalmic, diagnostic, and photographic equipments, but no further experience in operating the MP-1. To become familiar with the device and the software, the two operators read the MP-1 operation manual before commencing the study. The examinations were performed in random order with regard to the examiners, to prevent biasing of the results due to a possible learning effect. In between the two individual measurements (E1 and E2) of the same day, there was a break of at least $15 \mathrm{~min}$. Retinal sensitivity and stability of fixation were studied. The interexaminer variability resulted from the fluctuations in measurements between examiners (E1a and E2).

To analyse the intraexaminer reliability and variability, E1 performed an additional measurement (E1b) a week later. The intraexaminer variability resulted from the variation in the measurements obtained by E1 (E1a and E1b).

\section{Microperimeter MP-1}

Microperimetry was performed using the MP-1 (Nidek Technologies). A test grid with 41 stimulus locations was applied, covering an area of $10^{\circ}$ diameter. Goldmann III stimuli and a 4-2-1 staircase strategy were used. The stimuli were projected on a white background with background illumination set to $1.27 \mathrm{~cd} / \mathrm{m}^{2}(1.27 \mathrm{~cd} /$ $\mathrm{m}^{2}=4$ apostilbs; $1 \mathrm{asb}=0.31831 \mathrm{~cd} / \mathrm{m}^{2}$; stimulus intensity may be varied on $1(0.1 \mathrm{log})$ step scale from 0 to 20 decibels $(\mathrm{dB})$, where $0 \mathrm{~dB}$ represents the brightest luminance of $400 \mathrm{asb}=127 \mathrm{~cd} / \mathrm{m}^{2}$ ) and a stimulus presentation time of $200 \mathrm{~ms}$. A single cross of $2^{\circ}$ was used as fixation target in Groups 1 and 2; in Group 3, we used a single cross of $5^{\circ}$.The perimetric strategy of the MP-1 starts at an initially defined threshold level (12 dB) for each stimulus. A 4-2-1 staircase strategy is then implemented and the weakest recognized value is documented as the threshold for retinal sensitivity at each tested site. Light threshold in $\mathrm{dB}$ of all test locations was analysed for the study.

The fundus movements are tracked during examination while the patient gazes at the fixation target to assess fixation. ${ }^{20}$ The autotracking system calculates horizontal and vertical shifts relative to a reference frame and draws a map of the patient's eye movements during the examination. The recorded fixation points are classified into three categories for fixation analysis (stable, relatively unstable, unstable) in the manual of the 
MP-1 as well as in the literature. ${ }^{21}$ Fixation is defined as 'stable' if more than $75 \%$ of the fixation points are inside the $2^{\circ}$ diameter circle, as 'relatively unstable' if less than $75 \%$ are inside the $2^{\circ}$ diameter circle, but more than $75 \%$ inside the $4^{\circ}$ diameter circle, and as 'unstable' if less than $75 \%$ of the fixation sites are inside the $4^{\circ}$ diameter circle.

\section{Statistical methods}

The statistical tests were performed using SPSS v. 14.0.1 for Windows (SPSS Inc., Chicago, IL, USA) and MedCalc v. 9.4.1.0 (MedCalc Software, Mariakerke, Belgium).

All data were analysed with analysis of variance (ANOVA) test for repeated-measures ANOVA. Mean and standard deviations (SDs) of macular sensitivity were calculated for each group separately. To quantify reproducibility, the mean differences between the examiners and the SD of this difference were calculated to assess agreement. Subsequently, the $95 \%$ limits of agreement were charged, using Bland-Altman plots. ${ }^{2,23}$ To further assess reliability, the intraclass correlation coefficients (ICCs) were calculated from a two-way random effects model, for absolute agreement. Examination time was calculated with unpaired $t$-test comparing the different groups and paired $t$-test comparing the different examiners.

A $P$-value less than 0.05 was considered statistically significant.

\section{Results}

The mean age of Group 1 (9 women, 6 men) was $29 \pm 5$ years (range, 24-38 years), of Group 2 (8 women, 7 men) $75 \pm 7$ years (range, 64-86 years), and of Group 3

(3 women, 2 men) $74 \pm 7$ years (range, 63-81 years).

Best-corrected visual acuity in Group 1 was $-0.2 \pm 0.1 \log$ MAR (Snellen 20/12.5), in Group 2 $0.11 \pm 0.1 \log$ MAR (Snellen 20/25), and 0.2 $\pm 0.2 \log$ MAR (Snellen 20/32) in Group 3. Retinal thickness, quantified with the OCT, was $217 \pm 33 \mu \mathrm{m}$ in Group 1 , and $246 \pm 31$ and $297 \pm 10 \mu \mathrm{m}$ in Groups 2 and 3, respectively.

The mean differential light threshold is shown in Table 1 for each examiner and each group separately. The mean differential light threshold for all groups was $15.29 \pm 3.56 \mathrm{~dB}$ for E1a, $15.16 \pm 3.61 \mathrm{~dB}$ for E1b, and $15.27 \pm 3.38 \mathrm{~dB}$ for $\mathrm{E} 2$, respectively.

In Group 1, $100 \%$ of the participants showed a stable fixation. In Group 2, the fixation was stable in $55.56 \%$, relatively unstable in $33.33 \%$, and unstable in $11.11 \%$. A stable fixation in Group 3 was found in $66.67 \%$, a relatively unstable fixation in $26.67 \%$, and an unstable fixation in $6.67 \%$ (Table 2).

In Group 1, all participants showed stable fixation independent of the examiner. There was also no
Table 1 Mean differential light threshold in decibels (mean) and standard deviations of the mean differential light threshold (SD)

\begin{tabular}{|c|c|c|c|c|c|c|c|c|c|}
\hline & \multicolumn{3}{|c|}{ Young } & \multicolumn{3}{|c|}{ Old } & \multicolumn{3}{|c|}{$A R M D$} \\
\hline & $E 1 a$ & $E 1 b$ & E2 & E1a & $E 1 b$ & E2 & E1a & $E 1 b$ & $E 2$ \\
\hline Mean & 17.51 & 17.47 & 17.32 & 14.86 & 14.52 & 14.87 & 9.99 & 10.14 & 10.32 \\
\hline SD & 1.0 & 1.2 & 1.2 & 2.7 & 2.7 & 2.5 & 5.0 & 5.2 & 4.8 \\
\hline
\end{tabular}

Table 2 Fixation stability

\begin{tabular}{|c|c|c|c|c|c|c|c|c|c|}
\hline & \multicolumn{3}{|c|}{ Young } & \multicolumn{3}{|c|}{ Old } & \multicolumn{3}{|c|}{$A R M D$} \\
\hline & $E 1 a$ & $E 1 b$ & E2 & E1a & $E 1 b$ & E2 & E1a & $E 1 b$ & E2 \\
\hline Stable & 15 & 15 & 15 & 7 & 9 & 9 & 4 & 4 & 2 \\
\hline Relatively unstable & 0 & 0 & 0 & 6 & 5 & 4 & 1 & 1 & 2 \\
\hline Unstable & 0 & 0 & 0 & 2 & 1 & 2 & 0 & 0 & 1 \\
\hline
\end{tabular}

significant difference in fixation stability in Group 2, neither interexaminer nor intraexaminer (E1aE1b: $P=0.082$ and E1aE2: $P=0.433$, respectively). In Group 3, there was also no intra- or interexaminer difference in fixation stability (E1aE1b: $P=1.000$ and E1aE2: $P=0.208$, respectively).

The mean examination time in Group 1 was 13:04 $\pm 3: 58 \mathrm{~min}$ and the tracked time was $10.45 \pm 1: 53 \mathrm{~min}$. In Group 2, the mean examination time was $16: 09 \pm 6: 24 \mathrm{~min}$ and the tracked time was $10: 59 \pm 3: 07 \mathrm{~min}$. The mean examination time in Group 3 was 19:55 $\pm 7: 38 \mathrm{~min}$ and the tracked time was $11: 57 \pm 2: 51 \mathrm{~min}$. The examination time in Group 1 was significantly shorter than that in Group $2(P=0.006)$. The tracked time also showed a difference between Groups 1 and 2, but not statistically significant $(P=0.802)$. Examination time and tracked time between Groups 2 and 3 showed no statistically significant difference ( $P=0.052$ and $P=0.151$, respectively). Group 1 had a significant shorter examination and tracked time compared to Group $3(P<0.001$ and $P=0.027$, respectively).

\section{Interobserver variability}

The mean measurement differences between examiners E1a and E2 are shown in Table 3. The differences between the examiners were all nonsignificant using one-way ANOVA in either of the groups (Group 1: $P=0.381$; Group 2: $P=0.979$; and Group 3: $P=0.276$, respectively).

To assess agreement between both examiners, Bland-Altman plots were constructed. It could be seen that the limits of agreement were narrow with respect to the mean differential light threshold (Table 3). 
Table 3 Interexaminer variability

\begin{tabular}{lrrcrrr}
\hline & $\mathrm{N}$ & Mean $\pm S D$ & $95 \%$ CI & CV & LLA & ULA \\
\hline Young & 15 & $-0.184 \pm 0.787$ & $-0.25-0.62$ & 4.7 & -1.37 & 1.73 \\
Old & 15 & $-0.400 \pm 0.901$ & $-0.90-0.10$ & 8.7 & -1.90 & 1.90 \\
ARMD & 5 & $0.200 \pm 0.837$ & $-0.57-0.89$ & 17.9 & -1.52 & 0.84
\end{tabular}

Number of eyes $(N)$, mean of measurement differences between the two examiners (E1a and E2), standard deviation (SD) of measurement differences, coefficient of variation (CV) and lower (LLA) and upper (ULA) limit of agreement.

In Groups 1 and 2, all but one of the data points ( $n=15$ in each group) lay at or within 1.96 SDs of the mean. In Group 3, all data points $(n=5)$ lay at or within 1.96 SDs of the mean.

To further assess agreement, ICC was calculated and found to be 0.845 (95\% CI 0.538-0.948) in Group 1. In Group 2, the ICC was 0.964 (95\% CI 0.892-0.988) and 0.996 (95\% CI $0.963-1.000$ ) in Group 3, respectively. The analysis indicated good agreement in all the groups for two different examiners.

In Group 1, examination time was longer and tracked time was shorter when E1a performed the perimetry. The differences were not statistically significant $(P=0.171$ and $P=0.390$, respectively). E1a had statistically significant longer tracked time $(P=0.013)$ and not statistically significant longer examination times $(P=0.522)$ in Group 2. In Group 3, tracked time was slightly longer $(P=0.216)$ and examination time statistically significant shorter $(P=0.035)$ during the perimetries carried out by E1a.

\section{Intraobserver variability}

The mean measurement differences between the two examinations of E1 (E1a and E1b) are shown in Table 4. The differences between the examinations were all nonsignificant using one-way ANOVA in either of the groups (Group 1: $P=0.802$; Group 2: $P=0.135$; and Group 3: $P=0.577$, respectively).

Bland-Altman plots again showed that the limits of agreement were narrow with respect to the mean differential light threshold (Table 4).

In all the groups, all data points lay at or within 1.96 SDs of the mean.

To further assess agreement, the ICC was calculated and found to be 0.937 (95\% CI 0.813-0.979) in Group 1. In Group 2, the ICC was 0.976 (95\% CI 0.929-0.992) and 0.997 (95\% CI 0.967-1.000) in Group 3, respectively. The analysis indicated good agreement in all groups for two different examinations performed by one examiner.

Examination time and tracked time were longer $(P=0.110$ and $P=0.615$, respectively) in Group 1 in the first perimetries (E1a). In Groups 2 and 3, the first
Table 4 Intraexaminer variability

\begin{tabular}{lrllrrl}
\hline & $\mathrm{N}$ & Mean $\pm S D$ & $95 \% \mathrm{CI}$ & $\mathrm{CV}$ & \multicolumn{1}{l}{ LLA } & ULA \\
\hline Young & 15 & $-0.351 \pm 0.532$ & $-0.33-0.26$ & 3.1 & -1.01 & 1.07 \\
Old & 15 & $-0.304 \pm 0.830$ & $-0.79-0.12$ & 5.7 & -1.29 & 1.97 \\
ARMD & 5 & $0.160 \pm 0.589$ & $-0.57-0.89$ & 10.5 & -1.32 & 1.0 \\
\hline
\end{tabular}

Number of eyes $(N)$, mean of measurement differences between examinations of examiner E1 (E1a and E1b), standard deviation (SD) of measurement differences, coefficient of variation (CV) and lower (LLA) and upper (ULA) limit of agreement.

examinations (E1a) had slightly shorter tracked $(P=0.981$ and $P=0.436$, respectively) and examination times $(P=0.522$ and $P=0.173$, respectively).

\section{Discussion}

Any new diagnostic image device requires initial evaluation that includes reproducibility, reliability, and variability. As shown in an earlier study, the MP-1 provides reproducible threshold values, with a systematic difference of $11.4-18.3 \mathrm{~dB}$ compared to standard octopus perimetry. ${ }^{20}$ In another paper, results comparable to those obtained with the SLO perimetry were obtained. ${ }^{24}$ When perimetric findings based on the scotoma depths were compared, there was near-complete agreement between the SLO and MP-1 perimetry. Sawa et $a l^{25}$ found a larger scotoma size with MP-1 than with SLO in eight of 15 examined eyes. Using the MP-1 within a sensitive area of SLO scotometry, decreases in retinal threshold sensitivity were found in all the eyes. The location of the preferred retinal locus and fixation stability in the MP-1 fixation test significantly correlated with that in SLO scotometry.

In contrast to these comparable results regarding the newer devices, there are some less reliable results in the literature: Keltner et $a l^{26}$ described that $85.9 \%$ of abnormalities in visual field were not confirmed in the retests in the Ocular Hypertension Treatment Study and pointed out the importance of reproducible results for long-term follow-up. In a later study, the same group even found one or more normal tests on follow-up after confirmation of glaucoma by three consecutive, abnormal, reliable test results with the Humphrey Field Analyser in $12 \% .{ }^{27}$ These results suggest that either or both perimetric testing and early glaucomatous visual field loss may be inherently variable. ${ }^{27}$ As reported in earlier investigations, the amount of variability is much higher in patients with glaucomatous visual field loss; ${ }^{28-30}$ so the comparison with microperimetry in nonglaucomatous patients seems to be difficult.

In the current study, we evaluated the interexaminer and intraexaminer reliability of the MP-1. 
A mandatory condition for a reliable examination is stable reproducibility and operator-independent results. The reliability should first be tested in healthy volunteers with good compliance to prevent biasing due to possible influencing factors.

Our results suggest a good reliability, allowing examiner-independent measurements in different groups of participants.

A possible limiting factor of our study might be the small study population, but it has to be seen as a first attempt to evaluate reliability of MP-1. The results show good agreement in all the three groups and also in the total study population.

In Group 3, the ARMD patients, there was also no significant difference, neither interexaminer nor intraexaminer. But the inhomogeneity of the group is shown due to larger SDs of the mean differential light threshold and larger coefficients of variation. Although there was no statistically significant difference between Groups 2 and 3 for visual acuity, the ARMD patients needed larger fixation targets $\left(5^{\circ}\right.$ instead of $2^{\circ}$ ) to maintain stable fixation. In previous examinations with other ARMD patients, a single cross of $2^{\circ}$ as fixation target caused problems to maintain stable fixation.

These facts, as well as the variability within the group, caused us to plan an additional study with a larger sample size of ARMD patients with an adapted ARMD test grid (adapted stimulus arrangement in closer distribution, covering a smaller area).

Not surprisingly, examination and tracked times were shortest in Group 1, the longest times were found in Group 3. Between Groups 2 and 3, examination times were comparable, both groups with elderly patients. Regarding the interobserver variability, E1a tended to have longer examination times in all groups. This could be a hint for a possible operator dependency, because E1 was the newly recruited staff member with no further experience.

Concerning the intraobserver variability, a possible learning effect was found in Group 1, the healthy young volunteers, with shorter examination and tracked times in the second examination. A negative learning effect was found in Groups 2 and 3, with longer examination times. This could be explained by the gap of 1 week between the examinations, in which time, presumably, the older participants forgot the positive learning effect of the previous week. On the other hand, a learning effect performing perimetry even with monthly intervals is well described in the literature. ${ }^{31,32}$

Otherwise, these results could also be attributed to possible operator dependency, because the third examination was always performed by E1, the newly recruited staff member with no further experience.
Regarding the fixation stability, the elderly patients in Groups 2 and 3 showed multiple fixation losses. As mentioned above, ARMD patients needed a $5^{\circ}$ fixation cross instead of $2^{\circ}$ to maintain stable fixation. Therefore, more fixation losses are found in the older normal controls in Group 2 than in the ARMD patients in Group 3. Similar findings are found in the literature, in which age was a significant factor for fixation loss and therefore for unreliability of Humphrey visual field testing. ${ }^{33}$ Rohrschneider et $a^{34}$ also found a decrease of fixation stability with increasing age, even in normal subjects, evaluating SLO. In contrast, Kosnik et $a l^{35}$ described no age-dependent difference of fixation stability measured by a Scientific Research International Mark IV dual Purkinje image eye tracker. But older observers showed greater variability in their fixations along the horizontal meridian compared to the vertical meridian; ${ }^{35}$ these more eccentric movements might be measured as fixation losses more often.

The increasing number of patients with diabetic maculopathy ${ }^{36}$ and patients with $\mathrm{ARMD}^{37}$ highlight the need for a diagnostic instrument that allows a precise analysis of the central visual field and enables an exact correlation between fundus pathology and corresponding functional defects. Microperimetry may be of value in the follow-up of diabetic macular oedema (DME), as it incorporates a functional measure that completes the prognostic value of OCT and visual acuity. ${ }^{36}$ Significant correlations between mean retinal sensitivities measured by the MP-1, the foveal thickness in the OCT, and visual acuity were found in a retrospective chart review of patients with DME. ${ }^{38}$ Vujosevic et $a l^{36}$ compared the changes in macular sensitivity and macular thickness in different degrees of DME. They found macular sensitivity to be a relevant explanatory variable of visual function, independent of macular thickness data.

Varano et $a l^{39}$ showed a nonsignificant increase in visual acuity and macular sensitivity after photodynamic therapy in 14 myopic eyes with choroidal neovascularization.

In a previous study, we evaluated the potential benefit of macular function tests in patients with macular hole and macular pucker who underwent macular surgery. ${ }^{40}$ The results highlighted a significant improvement in central visual function after surgery in both the groups. We could demonstrate a significant increase in visual acuity, retinal sensitivity, and retinal fixation measured with the MP-1, whereas preferential hyperacuity perimeter measurements could not identify a significant difference in the pre- and post-operative results.

These studies point out that the MP-1 might be helpful for exact evaluation of macular function in patients with macular diseases. Our study demonstrates a good 
reliability, allowing examiner-independent

measurements.

\section{References}

1 Andersen MV. Scanning Laser Ophthalmoscope microperimetry compared with Octopus perimetry in normal subjects. Acta Ophthalmol Scand 1996; 74(2): 135-139.

2 Sunness JS, Schuchard RA, Shen N, Rubin GS, Dagnelie G, Haselwood DM. Landmark-driven fundus perimetry using the scanning laser ophthalmoscope. Invest Ophthalmol Vis Sci 1995; 36(9): 1863-1874.

3 Rohrschneider K, Fendrich T, Becker M, Krastel H, Kruse FE, Volcker HE. Static fundus perimetry using the scanning laser ophthalmoscope with an automated threshold strategy. Graefes Arch Clin Exp Ophthalmol 1995; 233(12): 743-749.

4 Rohrschneider K, Gluck R, Becker M, Holz FG, Kruse FE, Fendrich $\mathrm{T}$ et al. Scanning laser fundus perimetry before laser photocoagulation of well defined choroidal neovascularisation. Br J Ophthalmol 1997; 81(7): 568-573.

5 Rohrschneider K, Bultmann S, Gluck R, Kruse FE, Fendrich $\mathrm{T}$, Volcker HE. Scanning laser ophthalmoscope fundus perimetry before and after laser photocoagulation for clinically significant diabetic macular edema. Am J Ophthalmol 2000; 129(1): 27-32.

6 Sjaarda RN, Frank DA, Glaser BM, Thompson JT, Murphy RP. Assessment of vision in idiopathic macular holes with macular microperimetry using the scanning laser ophthalmoscope. Ophthalmology 1993; 100(10): 1513-1518.

7 Frenkel S, Slonim E, Horani A, Molcho M, Barzel I, Blumenthal EZ. Operator learning effect and interoperator reproducibility of the scanning laser polarimeter with variable corneal compensation. Ophthalmology 2005; 112(2): 257-261.

8 Blumenthal EZ, Williams JM, Weinreb RN, Girkin CA, Berry CC, Zangwill LM. Reproducibility of nerve fiber layer thickness measurements by use of optical coherence tomography. Ophthalmology 2000; 107(12): 2278-2282.

9 Gunvant P, Braodway DC, Watkiins RJ. Repeatability and reproducibility of the BVI ultrasonic Pachymeter. Eye 2003; 17: 825-828.

10 Sacu S, Findl O, Buehl W, Kiss B, Gleiss A, Drexler W. Optical biometry of the anterior eye segment: interexaminer and intraexaminer reliability of ACMaster. J Cataract Refract Surg 2005; 31(12): 2334-2339.

11 Lewis RA, Johnson CA, Keltner JL, Labermeier PK. Variability of quantitative automated perimetry in normal observers. Ophthalmology 1986; 93(7): 878-881.

12 Kim LS, McAnany JJ, Alexander KR, Fishman GA. Intersession repeatability of humphrey perimetry measurements in patients with retinitis pigmentosa. Invest Ophthalmol Vis Sci 2007; 48(10): 4720-4724.

13 Kiser AK, Mladenovich D, Eshraghi F, Bourdeau D, Dagnelie G. Reliability and consistency of dark-adapted psychophysical measures in advanced eye disease. Invest Ophthalmol Vis Sci 2006; 47(1): 444-452.

14 Katz J, Sommer A, Witt K. Reliability of visual field results over repeated testing. Ophthalmology 1991; 98(1): 70-75.

15 Bjerre A, Grigg JR, Parry NR, Henson DB. Test-retest variability of multifocal visual evoked potential and SITA standard perimetry in glaucoma. Invest Ophthalmol Vis Sci 2004; 45(11): 4035-4040.
16 Langelaan M, Wouters B, Moll AC, de Boer MR, vans Rens GH. Intra- and interrater agreement and reliability of the Functional Field Score. Ophthalmic Physiol Opt 2005; 25(2): 136-142.

17 Chan AB, Chauhan BC, LeBlanc RP, McCormick TA, Shaw AM. Intra- and interrater agreement with cumulative defect curves. J Glaucoma 1997; 6(2): 117-122.

18 Viswanathan AC, Crabb DP, McNaught AI, Westcott MC, Kamal D, Garway-Heath DF et al. Interobserver agreement on visual field progression in glaucoma: a comparison of methods. Br J Ophthalmol 2003; 87(6): 726-730.

19 Westling AK, Newland HS. Interrater agreement in oculo-kinetic perimetry-a screening test for glaucoma. Aust N Z J Ophthalmol 1995; 23(2): 125-128.

20 Springer C, Bultmann S, Volcker HE, Rohrschneider K. Fundus perimetry with the Micro Perimeter 1 in normal individuals: comparison with conventional threshold perimetry. Ophthalmology 2005; 112(5): 848-854.

21 Fujii GY, de Juan Jr E, Sunness J, Humayun MS, Pieramici DJ, Chang TS. Patient selection for macular translocation surgery using the scanning laser ophthalmoscope. Ophthalmology 2002; 109(9): 1737-1744.

22 Bland JM, Altman DG. Statistical methods for assessing agreement between two methods of clinical measurement. Lancet 1986; 1: 307-310.

23 Bland JM, Altman DG. Measuring agreement in method comparison studies. Stat Methods Med Res 1999; 8: 135-160.

24 Rohrschneider K, Springer C, Bultmann S, Volcker HE. Microperimetry-comparison between the micro perimeter 1 and scanning laser ophthalmoscope-fundus perimetry. Am J Ophthalmol 2005; 139(1): 125-134.

25 Sawa M, Gomi F, Toyoda A, Ikuno Y, Fujikado T, Tano Y. A microperimeter that provides fixation pattern and retinal sensitivity measurement. Jpn J Ophthalmol 2006; 50(2): 111-115.

26 Keltner JL, Johnson CA, Quigg JM, Cello KE, Kass MA, Gordon MO. Confirmation of visual field abnormalities in the Ocular Hypertension Treatment Study. Ocular Hypertension Treatment Study Group. Arch Ophthalmol 2000; 118(9): 1187-1194.

27 Keltner JL, Johnson CA, Levine RA, Fan J, Cello KE, Kass MA et al. Normal visual field test results following glaucomatous visual field end points in the Ocular Hypertension Treatment Study. Arch Ophthalmol 2005; 123(9): 1201-1206.

28 Chauhan BC, House PH, McCormick TA, LeBlanc RP. Comparison of conventional and high-pass resolution perimetry in a prospective study of patients with glaucoma and healthy controls. Arch Ophthalmol 1999; 117(1): 24-33.

29 Heijl A, Lindgren A, Lindgren G. Test-retest variability in glaucomatous visual fields. Am J Ophthalmol 1989; 108(2): 130-135.

30 Holmin C, Krakau CE. Variability of glaucomatous visual field defects in computerized perimetry. Albrecht Von Graefes Arch Klin Exp Ophthalmol 1979; 210(4): 235-250.

31 Matsuo H, Tomita G, Suzuki Y, Araie M. Learning effect and measurement variability in frequency-doubling technology perimetry in chronic open-angle glaucoma. J Glaucoma 2002; 11(6): 467-473.

32 Yenice O, Temel A. Evaluation of two Humphrey perimetry programs: full threshold and SITA standard testing strategy for learning effect. Eur J Ophthalmol 2005; 15(2): 209-212.

33 Birt CM, Shin DH, Samudrala V, Hughes BA, Kim C, Lee D. Analysis of reliability indices from Humphrey visual field 
tests in an urban glaucoma population. Ophthalmology 1997; 104(7): 1126-1130

34 Rohrschneider K, Becker M, Schumacher N, Fendrich T, Volcker HE. Normal values for fundus perimetry with the scanning laser ophthalmoscope. Am J Ophthalmol 1998; 126(1): 52-58.

35 Kosnik W, Fikre J, Sekuler R. Visual fixation stability in older adults. Invest Ophthalmol Vis Sci 1986; 27(12): 1720-1725.

36 Vujosevic S, Midena E, Pilotto E, Radin PP, Cheisa L, Cavarzeran F. Diabetic macular edema: correlation between microperimetry and optical coherence tomography findings. Invest Ophthalmol Vis Sci 2006; 47(7): 3044-3051.

37 Mukesh BN, Dimitrov PN, Leikin S, Wang JJ, Mitchell P, McCarty CA et al. Five-year incidence of age-related maculopathy: the Visual Impairment Project. Ophthalmology 2004; 111(6): 1176-1182.

38 Okada K, Yamamoto S, Mizunoya S, Hoshino A, Arai M, Takatsuna Y. Correlation of retinal sensitivity measured with fundus-related microperimetry to visual acuity and retinal thickness in eyes with diabetic macular edema. Eye 2006; 20: 805-809.

39 Varano M, Parisi V, Tedeschi M, Sciamanna M, Gallinaro G, Capaldo $\mathrm{N}$ et al. Macular function after PDT in myopic maculopathy: psychophysical and electrophysiological evaluation. Invest Ophthalmol Vis Sci 2005; 46(4): 1453-1462.

40 Richter-Mueksch S, Vécsei-Marlovits PV, Sacu S, Kiss C, Weingessel B, Schmidt-Erfurth U. Functional Macular Mapping in Patients with Vitreomacular Pathology before and after Surgery. Am J Ophthalmol 2007; 144(1): 23-31. 